\title{
Cardiovascular Alteration
}

National Cancer Institute

\section{Source}

National Cancer Institute. Cardiovascular Alteration. NCI Thesaurus. Code C41473.

Cardiovascular Alteration involves a change in the existing function of biologic molecules and complexes, or cellular, cell, or tissue components of the heart and vascular system by which blood is pumped and circulated through the body to provide tissues with oxygen and nutrients and to remove waste products. 